Keywords: Borderline personality disorder; Childhood traumatization; Physical abuse; Sexual abuse; Emotional abuse.

\title{
The role of childhood traumatization in the development of borderline personality disorder in Hungary
}

\author{
Katalin Merzaa,* \\ Gábor Papp ${ }^{b}$ \\ Ildikó Kuritárné Szabó, PhDa \\ a University of Debrecen, School of Public \\ Health, Department of Behavioral \\ Sciences, Debrecen \\ b University of Debrecen, Institute \\ of Psychology, Debrecen \\ HUNGARY
}

\begin{abstract}
Background and Objectives: There is a growing body of evidence suggesting the role of childhood abuse in the etiology of borderline personality disorder (BPD). Studies found that complex traumatization related to BPD include emotional/physical/sexual abuse and neglect. This study examines self-reported experiences of childhood traumatization in Hungarian inpatients with a diagnosis of borderline personality disorder and reveal which etiological factors are most strongly associated with the development of BPD.

Methods: Traumatic childhood experiences of 80 borderline inpatients, 73 depressed inpatients and 51 healthy controls were assessed with the Traumatic Antecedents Questionnaire and the Sexual Abuse Scale of Early Trauma Inventory.

Results: Adverse childhood experiences (neglect, emotional abuse, physical abuse, sexual abuse, witnessing trauma) were more prevalent among borderline patients than among depressed and healthy controls. Borderline patients reported severe sexual abuse, characterized by incest, penetration and repetitive abuse. Sexually abused borderline patients experienced more physical and emotional abuse than borderlines who were not sexually abused. The strongest predictors of borderline diagnosis were sexual abuse, intrafamilial physical abuse and neglect by the caretakers.

Conclusions: Overall, our results suggest that a reported childhood history of abuse and neglect are both common and highly discriminating for borderline patients in Hungary as well.
\end{abstract}




\section{Background and objectives}

The role of childhood traumatization in the etiology of borderline personality disorder (BPD) has been a focus of research for more than 30 years $^{1-4}$. North American and Western European studies have provided a large body of evidence on the numerous intrafamilial pathological childhood experiences, such as a history of physical, emotional, sexual abuse and neglect that are commonly reported by borderline patients ${ }^{1,4-}$ ${ }^{6}$. More specifically, $40-86 \%$ of subjects with BPD have reported being sexually abused during their childhood ${ }^{7-14}$, to a maximum of $94.7 \%$ reported by McLean and Gallop in $2003^{15}$. Furthermore, $10-73 \%$ have reported being physically abused by parents or adult caretakers $1,9,11,13,16,17$ and $17-25 \%$ have reported being physically neglected ${ }^{11,13}$. Threequarters of borderline patients have reported emotional abuse and $70 \%$ have reported childhood emotional withdrawal $^{13}$. In addition, findings of a large number of studies show that childhood experiences of both abuse and neglect are significantly more common among borderline patients than among comparisons with a diagnosis of Axis I or Axis II disorders ${ }^{2,11-13,18 . ~}$

Of all of the psychosocial factors, childhood sexual abuse is considered to be the most specific in the etiology of $\mathrm{BPD}^{19}$. Parameters of childhood sexual abuse highly discriminate between abused BPD patients and abused non-BPD patients ${ }^{20,21}$. Borderline patients compared to Axis I and II subjects have reported the most severe parameters of sexual abuse: significantly higher intra-familiar rates $(72 \%)^{15}$, no single incidents of abuse $(50 \%)^{11}$, multiple perpetrators $(35-79 \%)^{21,22}$, early-onset abuse $(13-60 \%)^{8,10,12,17,19}$, use of force $(93 \%)^{21}$ and penetration $(33-44 \%)^{8,11,21}$. Although studies have found that $40-75 \%$ of borderline patients are abused by a full-time adult caretaker ${ }^{9,23,24}$, reported childhood sexual abuse in borderline samples is perpetrated not only by parents. Moreover, reporting memories of sexual abuse by siblings, grandfathers or other family members could, in some cases, be a 'screen' for parental incest, which some may find intolerable to recall ${ }^{8}$.

However, sexual abuse is neither necessary, nor sufficient for the development of $\mathrm{BPD}^{13}$. A meta-analytic study of the published literature (containing 19 North-American and two European studies) before 1999, conducted by Fossati, Mededdu and Maf$\mathrm{fei}^{25}$, has found that in Western society there is only a moderate association between childhood sexual abuse and BPD diagnosis. Sexual abuse does not occur in a vacuum, it occurs in the context of other forms of abuse and dysfunctional parental behavior ${ }^{26,27}$ and contributes to the development of BPD through interaction with other pathological childhood experiences ${ }^{4,5}$. For example, sexually abused BPD patients are more likely to report physical neglect, emotional withdrawal, and inconsistent treatment by caretakers $^{13}$. They usually come from disturbed families which do not or cannot protect their children and fail to meet their needs ${ }^{2,8}$. Thus BPD patients have also reported significantly higher rates of psychiatric disorders in their families, especially anxiety disorders, depression, separation from parents, unfavorable parental rearing styles ${ }^{1}$, antisocial disorders and substance use disorder ${ }^{28,29}$. The findings of previous researches suggest that studies should assess a range of pathological childhood experiences, rather than focus solely on the prevalence of sexual abuse ${ }^{13}$.

Outside North-America and Western Europe, only a limited number of studies have examined the relationship between childhood abuse and borderline psychopathology. Recently, results emerging from studies conducted in Japan and China contribute to un- 
derstanding cross-cultural and culture-specific aspects of borderline etiology $30,31,32$. Consistent with prior North American and Western European research, both Japanese and Chinese studies have found that experiences of emotional, physical, sexual abuse, emotional and physical neglect are more prevalent among BPD patients than among non-BPD patients ${ }^{30,31,33}$. In these studies, the reported rate of childhood sexual abuse among borderline patients was lower than reported rates in North America, attributed by Huang ${ }^{30}$ to the lower rate of reported sexual abuse in the general population of China. In addition, in these studies only outpatient samples were used and the findings may not be generalizable to more severely disturbed inpatients ${ }^{30}$. The severity of childhood sexual abuse was also greater among BPD patients in China who had suffered incest, penetration and repetitive abuse ${ }^{30}$. Furthermore, Huang and colleagues ${ }^{30}$ used multivariate analyses to examine the variables which predict BPD. The results in China revealed that a combination of sexual abuse, maternal neglect, maternal physical abuse, and paternal antipathy were significant predictors of BPD, but none of these variables alone were predictive of $\mathrm{BPD}^{30}$. In the Japanese study, emotional abuse, emotional neglect and paternal overprotection were significant predictors of $\mathrm{BPD}^{31}$. The authors have assumed the results reflect differences between parenting styles in Western countries and the Far East, the latter being more collectivistic and the parenting style, more authoritarian, characterized by coercive control and low responsiveness ${ }^{31,32,34}$. Importantly, pathological childhood experiences are just a part of the more complex borderline etiology. The multifactorial model of the development of BPD suggests that the disorder results from the interaction and transaction of biological and environmental factors $^{35,36}$. Examining biological factors is outside the scope of this study.
In summary, childhood experiences of abuse are part of a cross-cultural etiology of BPD in North American and Western European countries as well as the Far East, but the relative contribution of particular forms of childhood abuse to the development of this disorder seems to vary across cultures.

A literature search has revealed that in Hungary and in the European Post-Soviet states there have been no studies that have investigated the role of traumatic childhood experiences in the development of BPD. The purposes of this study are to assess retrospectively the self-reported experiences of childhood traumatization in Hungarian inpatients with a diagnosis of BPD and to determine which etiological factors are most strongly associated with the development of BPD. Furthermore, we seek to reveal the differences between Hungarian and North-American/Western European borderline samples in order to understand the relative contributions of etiological factors that are culture-specific and others that are cross-cultural. Hungary and China both being countries with only relatively recent Post-Soviet histories, parents may not consider corporal punishment as abuse and, therefore, this parenting style may be correlated with higher prevalence of child physical abuse. We hypothesized that in our study physical abuse as a culture-specific factor would increase the risk for BPD. Furthermore, we assume that the major predictors (neglect, sexual abuse) of BPD in the Western societies would also associated with the development of BPD in Hungary.

In this study borderline inpatients were compared with depressed inpatients and a group of healthy individuals in the community. The control groups were initially chosen, because in sexual abuse research, chronic depression is often seen as a long-term result of

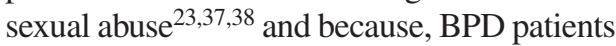
are rarely compared with a healthy control group with regard to childhood trauma ${ }^{1}$. 


\section{Methods}

\section{Participants and procedure}

The present study was conducted over the period from January 2013 to June 2013. The study followed the ethics declaration of Helsinki and prior to data collection the project was approved by the Hungarian Scientific and Medical Ethics Committee (ETT-TUKEB).

171 inpatients were recruited from eight Hungarian psychiatric hospitals. All patients were initially screened to determine that they 1) were between the ages of 18 and 50 years 2) had at least an average level of intellectual functioning and 3 ) had been given a definite or a probable clinical diagnosis of borderline personality disorder or major depressive disorder by a senior psychiatrist. Participants were excluded if they had current symptoms or a history of 1) bipolar mood disorder 2) major psychotic disorder or 3) cognitive impairment. After providing patients with a complete description of the study, written informed consent was obtained from each of them. The Hungarian version of Structured Clinical Interview for DSM-IV Axis I and Axis II disorders (SCID-I-II) ${ }^{39,40}$ was then administered to confirm the diagnosis of borderline personality disorder and major depressive disorder (MDD). 18 of 171 participants were eliminated by the diagnostic interview: 14 because they were found to have disorders excluded from this study, as above, and 4 because they met less than five BPD diagnostic criteria. Patients who met at least five DSM-IV criteria for BPD on the SCID-II were included in the borderline cohort. Patients who met the diagnosis of major depressive disorder without personality disorders were the non-borderline depressed controls. The interviews were conducted by the first author, a well-trained psychologist.

Healthy controls were recruited for the study from employees of local companies in
Debrecen. Out of a pool of 62 controls 51 were free of psychiatric disorders, as assessed by the SCID.

\section{Measures}

Experiences of childhood traumatization were assessed by the Traumatic Antecedents Questionnaire (TAQ) including in the Trauma Center Assessment Package ${ }^{41}$. The TAQ is a 42-item self-report questionnaire for gathering information about the frequency and severity of traumatic and adaptive experiences and it has been used by many researchers ${ }^{15,42}$. The process of the translation and adaptation of TAQ to Hungarian followed a standard procedure according to the guidelines for self-assessment instruments. Analysis of the psychometric properties of the TAQ is currently underway, and preliminary research showed satisfactory validity and reliability (with Cronbach alphas of 0.683-0.923).

In this study only 6 subscales of the TAQ were used, selected for the purpose of assessing traumatic or adverse experiences. These subscales cover neglect, separation, emotional abuse and physical abuse by a caretaker or family member, sexual abuse by an adult and witnessing of domestic violence. These adverse experiences were assessed at four different developmental periods: early childhood (0-6 years), latency ( $7-12$ years), adolescence (13-18 years), and adulthood (over 18 years). Responses can be scored 1 to 4 , with 1 corresponding to 'never or not at all', 2 to 'rarely or a little bit', 3 to 'occasionally or moderately', 4 to 'often or very much'. However, in this study the type of childhood traumatization was analyzed as a dychotomic variable (traumatized - non-traumatized), because we aimed to compare our results with the results of previous studies which also used dychotomic variables. The cut-off point was determined $2 / 3$, thus sub- 
jects who scored 1 ('never or not at all') or 2 ('rarely or little bit') in each item were considered non-traumatized, and subjects who scored 3 ('occasionally or moderately') or 4 ('often or very much') were considered traumatized. The $2 / 3$ cut-off point was initially chosen to prevent the overestimation of traumatic experiences in the sample.

Previous studies have indicated that the parameters of childhood sexual abuse have a specific relationship with the borderline diagnosis and highly discriminate abused BPD patients and abused non-BPD patients ${ }^{21}$. In view of this, we aimed to examine the parameters of sexual abuse in detail. In addition to the TAQ, the Sexual Abuse Scale of the Early Trauma Inventory (ETI) ${ }^{43}$ (with Cronbach alpha of 0.932) was used to assess childhood experiences of sexual abuse more accurately. The process of the translation of ETI Sexual Abuse Subscale to Hungarian language followed the standard protocol. Correlation analysis between the Sexual Abuse Scale of ETI and the sexual abuse subscale of TAQ showed that the scales measure the same construct $(r=0.88, p<0.001)$. The ETI defines sexual abuse as unwanted sexual contact performed solely for the gratification of the perpetrator, for the purpose of dominating or degrading the victim. This 15item scale gathers information about frequency, age at onset, use of force, relationship to the perpetrator and nature of sexual abuse at 4 developmental stages (similar to the developmental stages of the TAQ).

All assessments were done by the first author.

Between-group comparison of age involving continuous data were computed by means of one-way analysis of variance. Chi-square tests were performed to compare the frequency distributions of certain demographic characteristics, traumatic experiences and the nature of sexual abuse between the patient and the control groups. When cell sizes were 5 or less Fischer's exact test of probability was used. Logistic regression was used to test the research question regarding the possible predictors of BPD. A p value less than 0.05 was considered statistically significant. The statistical analyses were performed by the SPSS statistical package version 20.0.

\section{Results}

The final sample consisted of 204 participants, of whom 80 psychiatric inpatients were in the BPD group, 73 psychiatric inpatients were in the depressed comparison group and 51 people were in the healthy comparison group. Table 1 presents the comparison of demographic data among the three groups. To evaluate age differences among the groups one-way analysis of variance (ANOVA) was conducted. ANOVA revealed significant differences among the three groups $(F=49.42$, $p<0.001)$, the mean ages of the BPD group $(30.5 \pm 10.87$ years $)$ and of the healthy comparison group $(33.6 \pm 8.71)$ were significantly lower than of the depressed comparison group (44.3 \pm 5.91 years) according to the results of the Tukey test. Chi-square test for the categorical data showed significant differences in marital status $\left(\chi^{2}=88.72, p<0.001\right)$ and employment $\left(\chi^{2}=130.1, p<0.001\right)$ among the groups, with borderline patients less likely to be married and more likely to be unemployed than comparison subjects. The groups were found to be similar in sex distribution, with all groups containing significantly more females than males $\left(\chi^{2}=0.43, p=0.808\right)$. There were no statistically significant differences among the groups for education $\left(\chi^{2}=\right.$ 9.00, $p=0.061$ ). 
Table 1

Demographic characteristics of the borderline and depressed groups.

\begin{tabular}{|c|c|c|c|c|c|}
\hline \multirow[b]{2}{*}{$\begin{array}{l}\text { Demographic } \\
\text { characteristic }\end{array}$} & \multirow[b]{2}{*}{$\begin{array}{c}\text { BPD } \\
(\mathrm{N}=80)\end{array}$} & \multirow[b]{2}{*}{$\begin{array}{l}\text { Depressed } \\
(\mathrm{N}=73)\end{array}$} & \multirow[b]{2}{*}{$\begin{array}{l}\text { Healthy } \\
(\mathrm{N}=51)\end{array}$} & \multicolumn{2}{|c|}{ Analysis } \\
\hline & & & & $\chi^{2}$ & $P$ \\
\hline Age (Mean, SD)* & $30.5 \pm 10.87$ & $44.3 \pm 5.91$ & $33.6 \pm 8.71$ & & $<0.001$ \\
\hline \multicolumn{6}{|l|}{ Sex } \\
\hline Male & $12(15 \%)$ & $13(17.8 \%)$ & $7(13.7 \%)$ & $0.43(\mathrm{df}=2)$ & 0.808 \\
\hline Female & $68(85 \%)$ & $60(82.2 \%)$ & $44(86.3 \%)$ & & \\
\hline \multicolumn{6}{|l|}{ Marital status } \\
\hline Single & $50(62.5 \%)$ & $6(8.2 \%)$ & $19(37.0 \%)$ & $88.72(\mathrm{df}=8)$ & $<0.001$ \\
\hline Married & $3(3.8 \%)$ & $42(57.5 \%)$ & $12(24.0 \%)$ & & \\
\hline Common-law marriage & $10(12.5 \%)$ & $6(8.2 \%)$ & $16(31.0 \%)$ & & \\
\hline Divorced & $14(17.5 \%)$ & $14(19.2 \%)$ & $2(4.0 \%)$ & & \\
\hline Relict & $3(3.8 \%)$ & $5(6.9 \%)$ & $2(4.0 \%)$ & & \\
\hline \multicolumn{6}{|l|}{ Education } \\
\hline Primary school or below & $19(23.8 \%)$ & $13(17.8 \%)$ & $5(9.8 \%)$ & $9.00(\mathrm{df}=4)$ & 0.061 \\
\hline Secondary school & $51(63.8 \%)$ & $45(61.6 \%)$ & $30(58.8 \%)$ & & \\
\hline University & $10(12.5 \%)$ & $15(20.5 \%)$ & $16(31.4 \%)$ & & \\
\hline \multicolumn{6}{|l|}{ Employment } \\
\hline Unemployed & $30(37.5 \%)$ & $14(19.2 \%)$ & $2(3.9 \%)$ & $130.1(\mathrm{df}=12)$ & $<0.001$ \\
\hline Disabled & $13(16.3 \%)$ & $39(53.4 \%)$ & $0(0.0 \%)$ & & \\
\hline Full-time emloyment & $6(7.5 \%)$ & $6(8.2 \%)$ & $26(51.0 \%)$ & & \\
\hline Part-time employment & $6(7.5 \%)$ & $1(1.4 \%)$ & $2(3.9 \%)$ & & \\
\hline Temporary employment & $4(5.0 \%)$ & $0(0 \%)$ & $1(2.0 \%)$ & & \\
\hline Student & $16(20.0 \%)$ & $1(1.4 \%)$ & $19(37.3 \%)$ & & \\
\hline Other & $5(6.3 \%)$ & $12(16.4 \%)$ & $1(2.0 \%)$ & & \\
\hline
\end{tabular}

Note. $* F=49.42$.

Table 2 compares borderline patients and control subjects on overall rates of reported childhood traumatization, specifically, neglect by caretakers, separation from caretakers, intrafamilial emotional and physical abuse, intra/extrafamilial sexual abuse and witnessing family violence. A Chi-square test revealed significant differences among the groups for neglect $\left(\chi^{2}=35.88, p<0.001\right)$, emotional abuse $\left(\chi^{2}=34.36, p<0.001\right)$, physical abuse $\left(\chi^{2}=51.58, p<0.001\right)$, sexual abuse $\left(\chi^{2}=45.52, p<0.001\right)$ and witnessing trauma $\left(\chi^{2}=45.02, p<0.001\right)$ before the age of 18. There were no significant differences among the groups for separation $\left(\chi^{2}=5.19\right.$, $p=0.075)$. As seen in Table 3 , subsequent comparisons indicated that the rates of childhood neglect $\left(\chi^{2}=24.19, p<0.001 ; \chi^{2}=\right.$ 31.63, $p<0.001)$, emotional $\left(\chi^{2}=17.47, p<\right.$ $\left.0.001 ; \chi^{2}=33.77, p<0.001\right)$, physical $\left(\chi^{2}=\right.$ $\left.32.67, p<0.001 ; \chi^{2}=35.78, p<0.001\right)$, sexual abuse $\left(\chi^{2}=20.42, p<0.001 ; \chi^{2}=37.07\right.$, $p<0.001)$ and witnessing trauma $\left(\chi^{2}=12.02\right.$, $\left.p<0.001 ; \chi^{2}=44.95, p<0.001\right)$ were significantly higher in the BPD group than in depressed and healthy control groups. 
Table 2

Reported rates of childhood traumatization in the borderline group and the control groups before the age of 18 .

\begin{tabular}{|c|c|c|c|c|c|}
\hline \multirow[b]{2}{*}{$\begin{array}{l}\text { Type of } \\
\text { traumatization }\end{array}$} & \multirow[b]{2}{*}{$\begin{array}{c}\text { BPD } \\
(\mathrm{N}=80)\end{array}$} & \multirow[b]{2}{*}{$\begin{array}{c}\text { Depressed } \\
(\mathrm{N}=73)\end{array}$} & \multirow[b]{2}{*}{$\begin{array}{l}\text { Healthy } \\
(\mathrm{N}=51)\end{array}$} & \multicolumn{2}{|c|}{ Analysis } \\
\hline & & & & $\chi^{2}$ & $P$ \\
\hline Neglect & $69(86.3 \%)$ & $36(49.3 \%)$ & $20(39.2 \%)$ & 35.88 & $<0.001$ \\
\hline Separation & $64(80.0 \%)$ & $48(65.8 \%)$ & $41(80.4 \%)$ & 5.19 & 0.075 \\
\hline Emotional abuse & $70(87.5 \%)$ & $42(57.5 \%)$ & $20(39.2 \%)$ & 34.36 & $<0.001$ \\
\hline Physical abuse & $52(65.0 \%)$ & $14(19.2 \%)$ & $6(11.8 \%)$ & 51.58 & $<0.001$ \\
\hline Sexual abuse & $45(56.3 \%)$ & $15(20.5 \%)$ & $2(3.9 \%)$ & 45.52 & $<0.001$ \\
\hline Witnessing & $62(77.5 \%)$ & $37(50.7 \%)$ & $9(17.6 \%)$ & 45.02 & $<0.001$ \\
\hline
\end{tabular}

Table 3

Subsequent comparisons of the groups on reported rates of childhood traumatization.

\begin{tabular}{lcccr} 
& \multicolumn{2}{c}{ BPD vs. Depressed } & \multicolumn{2}{c}{ BPD vs. Healthy } \\
\cline { 2 - 5 } Type of traumatization & $\chi^{2}(\mathrm{df}=2)$ & \multicolumn{1}{c}{$P$} & $\chi^{2}(\mathrm{df}=1)$ & \multicolumn{1}{c}{$P$} \\
\hline Neglect & 24.19 & $<0.001$ & 31.63 & $<0.001$ \\
Separation & 3.94 & 0.047 & 0.003 & 0.956 \\
Emotional abuse & 17.47 & $<0.001$ & 33.77 & $<0.001$ \\
Physical abuse & 32.67 & $<0.001$ & 35.78 & $<0.001$ \\
Sexual abuse & 20.42 & $<0.001$ & 37.07 & $<0.001$ \\
Witnessing & 12.02 & $<0.001$ & 44.95 & $<0.001$ \\
\hline
\end{tabular}

Table 4 presents the prevalence of adverse experiences reported by the groups at the three age periods, early childhood (0-6 years), latency (7-12 years) and adolescence (13-18 years). A Chi-square test indicated significant differences among the groups for neglect, emotional, abuse, physical abuse, sexual abuse and witnessing trauma at each developmental period. There were no significant differences among the groups for separation at early childhood and adolescence. Table 4 shows the subsequent comparisons of the groups on the reported rates of childhood traumatization separately at each age period. Chi-square test indicated significant differences between the borderline and both control groups on most types of traumatization at each period. More specifically, a higher percentage of BPD patients than depressed and healthy comparisons reported having experienced neglect, emotional abuse, physical abuse, sexual abuse and witnessing trauma at early childhood, latency and adolescence. A significantly higher percentage of borderlines than depressed controls also reported separation during all three of these periods. However, at early childhood and adolescence borderline and healthy groups did not differ on reported rates of separation from caretakers. 


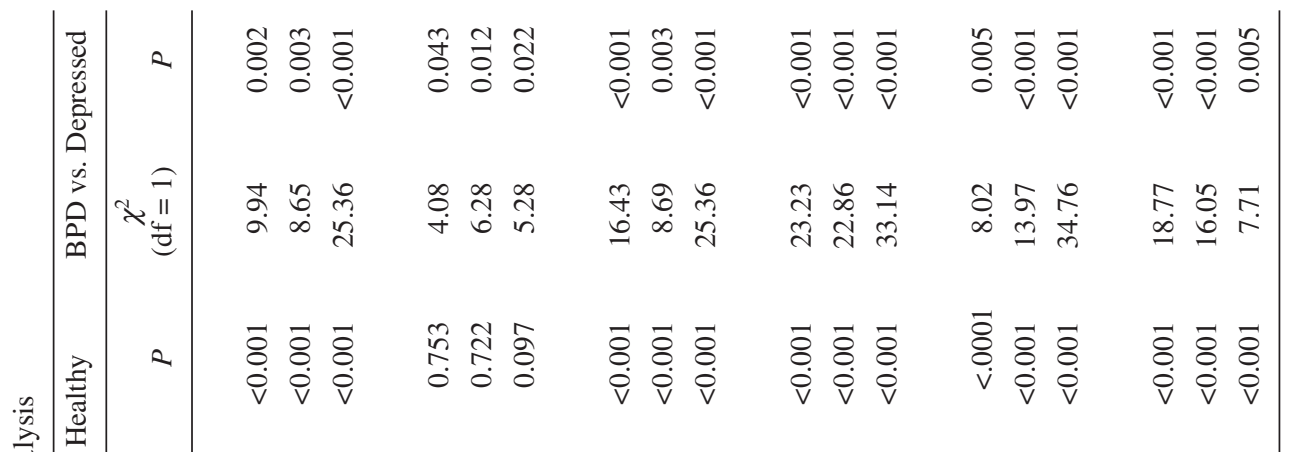

$$
\begin{aligned}
& \text { 究 }
\end{aligned}
$$

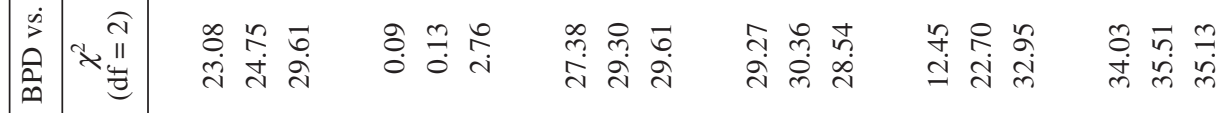

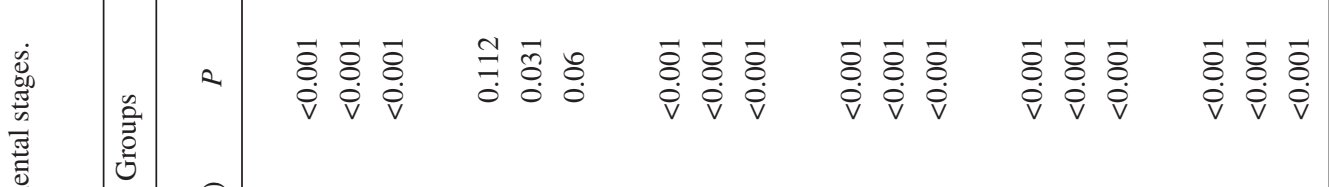

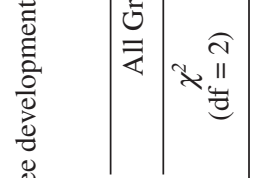

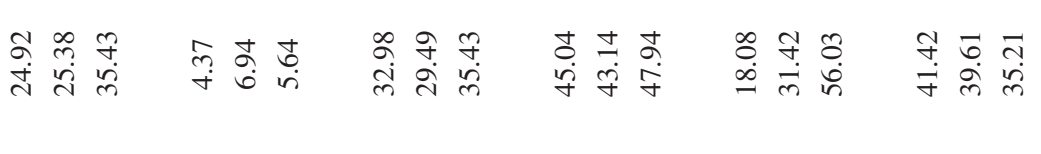

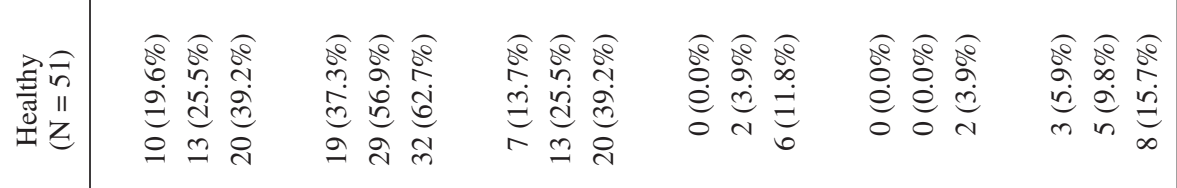

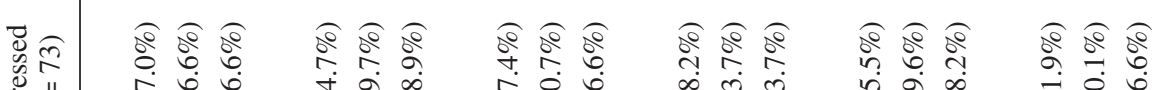

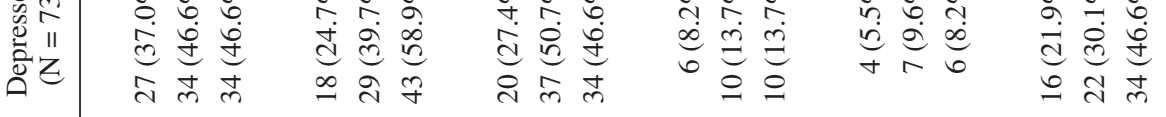

$$
\begin{aligned}
& \frac{0}{0}
\end{aligned}
$$

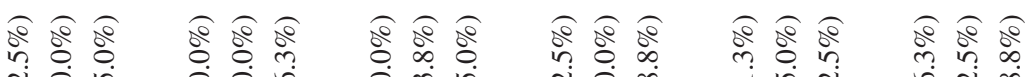

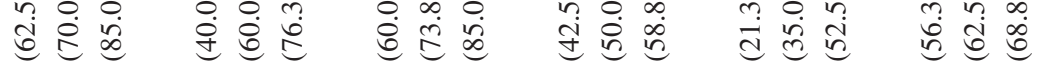

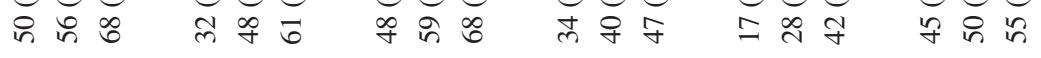

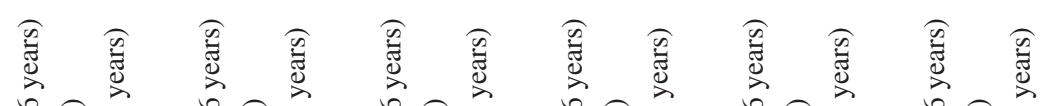

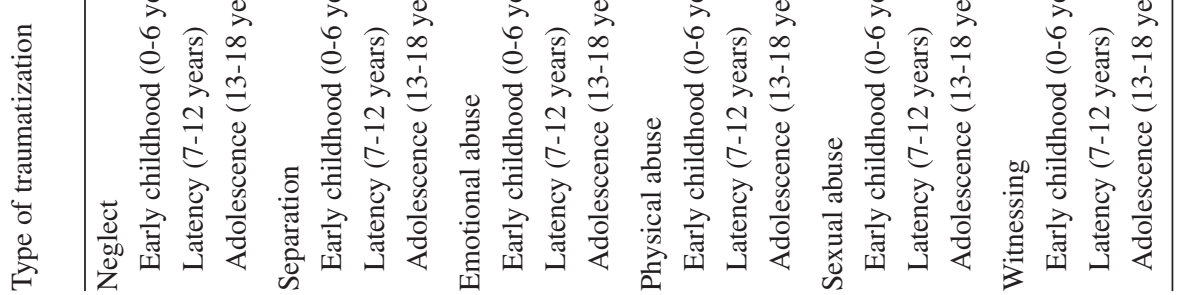

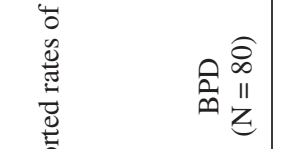


Table 5 compares borderline and depressed patients who reported childhood sexual abuse with respect to the parameters of sexual abuse. In this sample 45 borderline patients and 15 depressed comparisons reported having experienced sexual abuse before the age of 18 . For patients who had been abused by more than one perpetrator, data were entered for the specific perpetrator whose abuse would be expected to be more traumatic, according to the Paris \& Zweig-Frank's ${ }^{21}$ hierarchy. A significantly higher percentage of borderline patients than depressed comparisons reported childhood sexual abuse per- petrated by a father/male caretaker $\left(\chi^{2}=5.93\right.$, $p=0.015)$. Moreover, the frequency of multiple perpetrators was also higher among BPD patients $\left(\chi^{2}=9.27, p<0.001\right)$. More BPD patients reported abuse by perpetrators familiar to them $\left(\chi^{2}=0.86, \mathrm{p}=0.353\right)$, and by brothers $\left(\chi^{2}=0.69, p=0.41\right)$, but these differences were not significant. Furthermore, the rate of childhood sexual abuse by a male stranger was significantly higher in the depressed control group $\left(\chi^{2}=4.69, p=0.03\right)$. There was a large, significant difference between the groups with respect to the nature of childhood sexual abuse. The prevalence of

Table 5

Parameters of childhood sexual abuse in the borderline group and in the depressed control group.

\begin{tabular}{|c|c|c|c|c|}
\hline \multirow[b]{2}{*}{ Parameters } & \multirow[b]{2}{*}{$\mathrm{BPD}(\mathrm{N}=45)$} & \multirow[b]{2}{*}{ Depressed $(\mathrm{N}=15)$} & \multicolumn{2}{|c|}{ Analysis } \\
\hline & & & $\chi^{2}(\mathrm{df}=1)$ & $P$ \\
\hline \multicolumn{5}{|l|}{ Perpetrator } \\
\hline Father/Male caretaker & $22(48.9 \%)$ & $2(13.3 \%)$ & 5.93 & 0.015 \\
\hline Brother & $2(4.4 \%)$ & $0(0.0 \%)$ & 0.69 & 0.41 \\
\hline Other male & $18(40.0 \%)$ & $4(26.7 \%)$ & 0.86 & 0.353 \\
\hline Other female & $2(4.4 \%)$ & $0(0.0 \%)$ & 0.69 & 0.406 \\
\hline Male stranger & $13(28.9 \%)$ & $9(60.0 \%)$ & 4.69 & 0.03 \\
\hline Multiple & $19(42.2 \%)$ & $0(0.0 \%)$ & 9.27 & $<0.001$ \\
\hline \multicolumn{5}{|l|}{ Nature } \\
\hline Fondling & $43(95.6 \%)$ & $13(86.7 \%)$ & 1.43 & 0.232 \\
\hline Oral sex & $23(51.1 \%)$ & $3(20.0 \%)$ & 4.43 & 0.035 \\
\hline Penetration & $34(75.6 \%)$ & $3(20.0 \%)$ & 14.68 & $<0.001$ \\
\hline Incomplete penetration & $33(73.3 \%)$ & $6(40.0 \%)$ & 5.49 & 0.019 \\
\hline Anal penetration & $2(4.4 \%)$ & $0(0.0 \%)$ & 0.69 & 0.406 \\
\hline \multicolumn{5}{|l|}{ Frequency } \\
\hline Single incident & $8(17.8 \%)$ & $9(60.0 \%)$ & 9.87 & 0.002 \\
\hline More than once a year & $10(22.2 \%)$ & $5(33.3 \%)$ & 0.124 & 0.389 \\
\hline Monthly & $18(40.0 \%)$ & $1(6.7 \%)$ & 5.77 & 0.016 \\
\hline Weekly & $5(11.1 \%)$ & $0(0.00 \%)$ & 1.82 & 0.178 \\
\hline Daily & $4(8.9 \%)$ & $0(0.00 \%)$ & 1.43 & 0.232 \\
\hline \multicolumn{5}{|l|}{ Age at onset } \\
\hline Early childhood 0-6 years & $17(37.8 \%)$ & $4(26.7 \%)$ & 0.61 & 0.435 \\
\hline Latency $7-12$ years & $18(40.0 \%)$ & $5(33.3 \%)$ & 0.212 & 0.646 \\
\hline Adolescence $13-18$ years & $10(22.2 \%)$ & $6(40.0 \%)$ & 0.182 & 0.178 \\
\hline
\end{tabular}


oral sex $\left(\chi^{2}=4.43, p=0.035\right)$, penetration $\left(\chi^{2}\right.$ $=14.68, p<0.001)$ and incomplete penetration $\left(\chi^{2}=5.49, p=0.019\right)$ was higher among borderline patients than among depressed patients. The groups did not differ significantly in the prevalence of fondling $\left(\chi^{2}=1.43, p=\right.$ $0.232)$ and anal penetration $\left(\chi^{2}=.69, p=\right.$ 0.406 ). The prevalence of monthly regular sexual abuse was significantly higher among BPD patients than among depressed controls before the age of $18\left(\chi^{2}=5.77, p=0.016\right)$. A higher percentage of borderline patients experienced weekly $\left(\chi^{2}=1.82, p=0.178\right)$ and daily $\left(\chi^{2}=1.43, p=0.232\right)$ regular sexual abuse, but these differences were not significant. The rate of single incidents was significantly higher in the depressed group $\left(\chi^{2}\right.$ $=9.87, p=0.002$ ). Statistical analysis revealed no significant difference between the groups regarding the age of the first sexual abuse event (Early childhood: $\chi^{2}=0.61, p=$ 0.435 ; Latency: $\chi^{2}=0.212, p=0.646$; Adolescence: $\chi^{2}=0.182, p=0.178$ ) Table 6 compares the rates of childhood neglect, separation, emotional abuse, physical abuse and witnessing, reported by borderline patients with a history of childhood sexual abuse and without a history of childhood sexual abuse.
A Chi-square test revealed significant differences between the groups. The prevalence of separation $\left(\chi^{2}=7.94, p=0.005\right)$, emotional abuse $\left(\chi^{2}=14.69, p<0.001\right)$, physical abuse $\left(\chi^{2}=17.09, p<0.001\right)$ and witnessing trauma $\left(\chi^{2}=24.25, p=0.005\right)$ was significantly higher in the group of sexually abused borderline patients. The groups were not significantly different on reported rates of neglect $\left(\chi^{2}=2.05, p=0.152\right)$.

Logistic regression was carried out to determine the strongest predictors of BPD diagnosis. The dependent variable was the diagnosis of BPD or not, and the independent variables were the types of childhood traumatization (neglect, separation, emotional abuse, physical abuse, sexual abuse, witnessing trauma) and the parameters of sexual abuse (nature, perpetrator, frequency, age at onset). Table 7 presents the variables that significantly predicted the BPD diagnosis in the logistic regression model. The highest odds ratio for predicting BPD diagnosis was found for childhood experiences of genital fondling (Odds Ratio $=8.156$ ), followed by penetration, intrafamilial physical abuse and neglect by the caretakers (Odds Ratio $=5.316,4.248$, 4.083 respectively).

Table 6

Pathological childhood experiences of sexually abused and not sexually abused borderline patients.

\begin{tabular}{lcccccr} 
& & & & \multicolumn{2}{c}{ Analysis } \\
\cline { 6 - 7 } & BPD patients $(\mathrm{N}=45)$ & BPD patients $(\mathrm{N}=35)$ & & $\chi^{2}(\mathrm{df}=1)$ & $P$ \\
\hline Neglect & 41 & $91.1 \%$ & 28 & $80.8 \%$ & 2.05 & 0.152 \\
Separation & 41 & $91.1 \%$ & 23 & $65.7 \%$ & 7.94 & 0.005 \\
Emotional abuse & 45 & $100 \%$ & 23 & $71.4 \%$ & 14.69 & $<0.001$ \\
Physical abuse & 38 & $84.4 \%$ & 14 & $40.0 \%$ & 17.09 & $<0.001$ \\
Witnessing & 44 & $97.8 \%$ & 18 & $51.4 \%$ & 24.25 & $<0.001$ \\
\hline
\end{tabular}


Table 7

Significant risk factors associated with the diagnosis of borderline personality disorder.

\begin{tabular}{lcccccccc} 
& & & & & & & \multicolumn{2}{c}{$\begin{array}{c}\text { 95.0\% C.I. for } \\
\text { Odds Ratio }\end{array}$} \\
\cline { 7 - 9 } Variables & Beta & $\mathrm{SE}$ & $\mathrm{df}$ & $P$ & Odds Ratio & Lower & Upper \\
\hline Genital fondling & 2.099 & 0.608 & 1 & 0.001 & 8.156 & 2.479 & 26.836 \\
Penetration & 1.671 & 0.780 & 1 & 0.032 & 5.316 & 1.152 & 24.535 \\
Neglect & 1.407 & 0.491 & 1 & 0.004 & 4.083 & 1.560 & 10.686 \\
Physical abuse & 1.446 & 0.475 & 1 & 0.002 & 4.248 & 1.673 & 10.786 \\
\hline
\end{tabular}

\section{Discussion}

To the best of our knowledge, in Hungary and in the European Post-Soviet states there have been no studies that have investigated the role of traumatic childhood experiences in the development of BPD. The primary aim of this study was to explore the relationship between childhood traumatic experiences and BPD in Hungary. We have used well-researched questionnaires to assess intrafamilial forms of adverse childhood experiences, including neglect, separation, emotional abuse, physical abuse, sexual abuse and witnessing trauma.

Five important findings emerged from this study. First, our findings are consistent with the large number of studies demonstrating that self-reported histories of both neglect and abuse are common among patients with the diagnosis of BPD. Our results indicated that $86 \%$ of borderline patients had experienced emotional neglect, including parental disinterest, underinvolvement, and physical neglect by caretakers. Moreover, the prevalence of prolonged separations from caretakers was $80 \%$ in the borderline group. In terms of abuse, $88 \%$ of borderline patients reported a childhood history of emotional abuse, $65 \%$ reported physical abuse and 56\% reported sexual abuse. The prevalence of both abuse and neglect identified in this study falls within the ranges found in Western and Far Eastern societies.

Second, we have found that adverse childhood experiences, including neglect, emotional abuse, physical abuse, sexual abuse and witnessing trauma were more prevalent among borderline patients than among depressed and healthy comparisons in all three developmental periods. These findings are consistent with the results of previous studies from Western societies and the Far East which have found that childhood experiences of both abuse and neglect are significantly more common among borderline patients than among

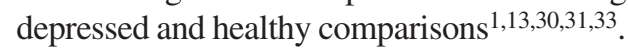

Third, we have found that borderline patients reported experiences of severe sexual abuse, characterized by incest, penetration and repetitive abuse. Furthermore, our results are consistent with the findings of previous studies showing that borderline patients compared to Axis I patients have reported the most severe forms of sexual abuse $^{8,11,44}$. More specifically, severely impaired borderline inpatients in our study reported more incest (49\%), monthly regular abuse $(40 \%)$, multiple perpetrators $(42 \%)$, abuse before the age of $6(13 \%)$ and penetration $(76 \%)$ than depressed controls. 
Fourth, we have found that sexually abused borderline patients seemed to come from more chaotic family environments than borderline patients who were not sexually abused. More specifically, they were more likely to report having been emotionally and physically abused. Our results are consistent with the findings of previous studies suggesting that sexual abuse does not occur in a vacuum but in the context of other forms of abuse and dysfunctional parental behavior, all of which are likely to be contributing to the development of BPD through interactions with other pathological childhood experiences $^{2,13,26}$.

Lastly, we have found that sexual abuse (particularly, genital fondling and penetration), intrafamilial physical abuse and neglect by caretakers were the strongest predictors of borderline diagnosis. These findings are consistent with the findings of North American and European studies ${ }^{13,45}$ and suggest that, beside sexual abuse, neglect is an important factor in the development of BPD. On the other hand, physical abuse was a predictor of borderline etiology in Hungary and in the Far East $^{30}$ but not in Western studies.

There are several limitations of this study. First, the BPD patients in this study were severely disturbed inpatients with a history of childhood physical and/or sexual abuse, therefore, these findings may not be generalizable to outpatients who suffer milder forms of BPD. The second limitation of the study is the selfreported, retrospective assessment of childhood traumatic events. Dissociation from the memory of a childhood history of severe physical and sexual abuse may lead to the underreporting of such experiences ${ }^{46}$. Furthermore, borderline patients, who suffer from distorted perceptions of the world, may be particularly susceptible to false memories. Lastly, we did not study protective factors.
To get a more nuanced picture about the etiology of BPD, future studies should consider a wider range of pathological and protective childhood experiences, including caretaker psychopathology to which patients may have been exposed as children.

\section{Conclusions}

Our results suggest that self-reported childhood history of abuse and neglect are both common and highly discriminating for borderline patients in Hungary as well. These results suggest that childhood sexual abuse and neglect can be seen as a part of a cross-cultural etiology of BPD. Our study fit into the range of studies, which highlight the association between childhood traumatization and the development of BPD in countries with different sociocultural backgrounds. As for the type of childhood traumas, like Huang's ${ }^{30}$ study in China, our findings also give weight to the role of physical abuse in the development of BPD. In societies with authoritarian traditions corporal punishment usually has a more major role in child rearing. Hungary and China both being countries with only relatively recent Post-Soviet histories, parents may not consider corporal punishment as abuse and, therefore, the use of physical force may be more prevalent. Furthermore, patients can easier report experiences of physical abuse than sexual abuse in a society, where sexual abuse may be still a taboo topic.

This study will, hopefully, encourage Hungarian clinicians to assess the childhood experiences of borderline patients more thoroughly, bringing the high likelihood of childhood abuse to clinicians' attention. A better appreciation of the possible childhood abuse experiences of borderline patients may, hopefully, help clinicians view them as survivors of abuse with specific treatment needs. 


\section{Acknowledgement}

This research was realized in the frames of TÁMOP 4.2.4. A/1-11-1-2012-0001 "National Excellence Program - Elaborating and operating an inland student and researcher personal support system" The project was subsidized by the European Union and co-financed by the European Social Fund.

\section{References}

1. Bandelow B, Krause J, Wedekind D, Broocks A, Hajak G, Rüther E. Early traumatic life events, parental attitudes, family history, and birth risk factors in patients with borderline personality disorder and healthy controls. Psychiatry Res. 2005; 134(2): 169-79.

2. Helgeland MI, Torgesen S. Developmental antecedents of borderline personality disorder. Compr Psychiatry. 2004; 45(2): 138-47.

3. Hernandez A, Arntz A, Gaviria AM, Labard A, Gutierrez-Zotes JA. Relationships between childhood maltreatment, parenting style, and borderline personality disorder criteria. J Pers Disord. 2012; 26(5): 727-36.

4. Zanarini MC. Childhood experiences associated with the development of borderline personality disorder. Psychiatr Clin North Am. 2000; 23: 89-101.

5. Sabo AN. Etiological significance of associations between childhood trauma and borderline personality disorder: Conceptual and clinical implications. J Pers Disord. 1997; 11: 50-70.

6. Wingenfeld K, Schaffrath C, Rullkoetter N, Mensebach C, Schlosser N, Beblo T. Associations of childhood trauma, trauma in adulthood and previous-year stress with psychopathology in patients with major depression and borderline personality disorder. Child Abuse Neglect. 2011; 35: 647-54.

7. Links PS, Steiner M, Offord DR, Eppel A. Characteristics of borderline personality disorder: A Canadian study. Can J Psychiatry. 1988; 33: 336-40.

8. Ogata SN, Silk KR, Goodrich S, Lohr NE, Westen D, Hill EM. Childhood sexual and physical abuse in adult patients with borderline personality disorder. Am J Psychiatry. 1990; 147: 1008-13.

9. Paris JP, Zweig-Frank H, Guzder J. Psychological risk factors for borderline personality disorder in female patients. Compr Psychiatry. 1994; 35(4): 301-305.
10. Shearer SL, Peters CP, Quaytman MS, Ogden RL. Frequency and correlates of childhood sexual and physical abuse histories in adult female borderline inpatients. Am J Psychiatry. 1990; 147: 214-16.

11. Silk KR, Lee S, Hill EM, Lohr NE. Borderline personality disorder symptoms and severity of sexual abuse. Am J Psychiatry. 1995; 152: 1059-64.

12. Westen D, Ludolph P, Misle B, Ruffins S, Block J. Physical and sexual abuse in adolescent girls with borderline personality disorder. Am J Orthopsychiatry. 1990; 60: 55-66.

13. Zanarini MC, Williams AA, Lewis RE, Reich RB, Vera SC, Marino MF. Reported pathological childhood experiences associated with the development of borderline personality disorder. Am J Psychiatry. 1997; 154: 1101-06.

14. Zanarini MC, Laudate CS, Frankenburg FR, Reich DB, Fitzmaurice G. Predictors of self-mutilation in patients with borderline personality disorder: A 10-year follow-up study. J Psychiatr Res. 2011; 45: 823-28.

15. McLean LM, Gallop R. Implications of childhood sexual abuse for adult borderline personality disorder and complex posttraumatic stress disorder. Am J Psychiatry. 2003; 160: 369-71.

16. Golier JA, Yehuda R, Briere LM, Mitropoulou V, New AS, Schmeidler J, et al. The relationship of borderline personality disorder to posttraumatic stress disorder and traumatic events. Am J Psychiatry. 2003; 160: 2018-24.

17. Zanarini MC, Gunderson JG, Marino MF, Schwartz EO, Frankenburg FR. Childhood experiences of borderline patients. Compr Psychiatry. 1989; 30: 18-25.

18. Sansone RA, Lam C, Wiederman MW. Being bullied in childhood: Correlations with borderline personality in adulthood. Compr Psychiatry. 2010; 51:458-61.

19. Van der Kolk BA, Herman JL. Childhood trauma in borderline personality disorder. Am J Psychiatry. 1989; 146: 490-95.

20. Kuritárné Szabó I. Borderline személyiségzavar. Tünettan, etiológia, terápia. Budapest: Medicina Könyvkiadó. 2008.

21. Paris JP, Zweig-Frank H. Parameters of childhood sexual abuse in female patients. In: Zanarini MC, ed. Role of sexual abuse in the etiology of borderline personality disorder. Washington, DC: American Psychiatric Press, Inc. 1997; 15-28.

22. McClellan J, Adams J, Douglas D, McCurry C, Storck M. Clinical characteristics related to severity of sexual abuse: A study of seriously mentally ill youth. Child Abuse Negl. 1995; 19: 1245-1254.

23. Figueroa EF, Silk KR, Huth A, Lohr NE. History of childhood sexual abuse and general psychopathology. Compr Psychiatry. 1997; 38: 23-30. 
24. Zanarini MC, Yong L, Frankenburg FR, Hennen J, Reich DB, Marino MF. Severity of reported childhood sexual abuse and its relationship to severity of borderline psychopathology and psychosocial impairment among borderline inpatients. J Nerv Ment Dis. 2002; 190(6): 381-87.

25. Fossati A, Mededdu F, Maffei C. Borderline personality disorder and childhood sexual abuse: A meta-analyticstudy. J Pers Disord. 1999; 13(3): 268-80.

26. Briere JN. Child abuse trauma. Theory and treatment of the lasting effects. Newbury Park: SAGE Publications, Inc. 1992.

27. Kroll J. Etiologic theories of borderline personality disorder: A commentary. In: Paris, J, ed. Borderline personality disorder. Etiology and treatment. Washington, DC: American Psychiatric Press, Inc. 1993; 211-26.

28. Goldman SJ, D’Angelo EJ, DeMaso DR. Psychopathology in the families of children and adolescents with borderline personality disorder. Am J Psychiatry. 1993; 150: $1832-35$.

29. Harman MJ. Children at risk for borderline personality disorder. Journal of Contemporary Psychotherapy. 2004; 34: 279-90.

30. Huang J, Yang Y, Wu J, Napolitano LA, Xi Y, Cui Y. Childhood abuse in Chinese patients with borderline personality disorder. J Pers Disord. 2012; 26: 238-54.

31. Machizawa-Summers S. Childhood trauma and parental bonding among Japanese female patients with borderline personality disorder. Int J Psychol. 2007; 42(4): 265-73.

32. Zhang TH, Chow A, Wang LL, Yu JH, Dai YF, Lu X, et al. Childhood maltreatment profile in a clinical population in China: A further analysis with existing data of an epidemiologic survey. Compr Psychiatry. 2013; 54: 856-64.

33. Zhang TH, Chow A, Wang LL, Dai YF, Xiao ZP. Role of childhood traumatic experience in personality disorders in China. Compr Psychiatry. 2012; 53: 829-36.

34. Wu P, Robinson CC, Yang C, Hart CH, Olsen DF, Porter CL, et al. Similarities and differences in mother's parenting of preschoolers in China and the United States. Int J Behav Dev. 2002; 26: 481-91.

35. Linehan MM. Cognitive-behavioral treatment of borderline personality disorder. New York: The Guilford Press. 1993.

36. Maffei C. Borderline personality disorder: From clinical heterogenity to diagnostic coherence. In: Maj M, Akiskal H, Mezzich J, Okasha A, eds. Personality Disorders. West Sussex: Wiley. 2005; 248-50.
37. Arnow BA. Relationships between childhood maltreatment, adult health and psychiatric outcomes, and medical utilization. J Clin Psychiatry. 2004; 65: 10-15.

38. Zlotnick C, Mattia JI, Zimmerman M. Clinical features of survivors of sexual abuse with major depression. Child Abuse Negl. 2001; 25: 357-67.

39. Szádóczky E, Rózsa S, Unoka Zs. Strukturált klinikai interjú a DSM-IV I. tengely zavarainak felmérésére. Budapest: OS Hungary Tesztfejlesztő. 2006.

40. Szádóczky E, Unoka Zs, Rózsa S. Strukturált klinikai interjú a DSM-IV II. tengelyén található személyiségzavarok felmérésére. Budapest: OS Hungary Tesztfejlesztő. 2004.

41. Van der Kolk BA, Smyth N. Trauma Assessment Packet. [CD-ROM]. The Trauma Center at Justice Resource Institute, University of Buffalo School of Social Work. 2010.

42. Saxe GN, Van der Kolk BA, Berkowitz R, Chinman, G, Hall K, Leiberg G, et al. Dissociative disorders in psychiatric inpatients. Am J Psychiatry. 1993; 150: 1037-42.

43. Bremner JD, Bolus R, Mayer EA. Psychometric properties of the Early Trauma Inventory-Self Report. J Nerv Ment Dis. 2007; 195: 211-18.

44. Weaver TL, Clum GA. Early family environments and traumatic experiences associated with borderline personality disorder. J. Consult Clin Psychol. 1993; 61: 1068-75.

45. Lobbestael J, Arntz A, Berstein DP. Disentangling the relationship between different types of childhood maltreatment and personality disorders. J Pers Disord. 2010; 24: 285-95.

46. Herman JL, Harvey MR. Adult memories of childhood trauma: A naturalistic clinical study. J Trauma Stress. 1997; 10: 557-71.

\footnotetext{
* Corresponding author:

Katalin Merza

University of Debrecen

School of Public Health

Department of Behavioral Sciences

Nagyerdei krt. 98. P.O.Box: 45

H-4032 Debrecen

Hungary

Tel. +36 $52411717 / 56531$

Fax: +36 52255723

E-mail: merza.katalin@sph.unideb.hu
} 